\title{
Clinical Reasoning: A 26-year-old man with right hand and arm weakness
}

Emily J. Elliott, DO, and Jonathan K. Smith, MD

Neurolog $y^{\circledR}$ 2019;93:e927-e933. doi:10.1212/WNL.0000000000008006
Correspondence

Dr. Elliott

emily.j.elliott4.mil@mail.mil

\section{Section 1}

A 26-year-old infantryman developed right hand and arm weakness while deployed to Iraq. Extension of the right second digit worsened over 2 weeks, followed by difficulty extending digits 3-5 over the following weeks. He reported muscle twitching in the right upper extremity over the same period, and that his thumb would lock or cramp in an opposed position during use. He denied pain, motor, or sensory symptoms in other extremities. Nine months prior, he sustained an injury while parachuting during airborne school, resulting in a concussion, headache, and neck and back pain, but no weakness.

Over the next 2 years, he noted wasting of his right hand intrinsics and decreasing strength with triceps curls, bench press, and grip. He did not seek medical attention until he injured his left wrist while weight-lifting, at which point he was referred to a military treatment facility due to his right hand atrophy. He reported that the weakness and atrophy had stabilized, but that over the prior 6 months he had developed intermittent numbness in both hands when lifting weights, plus tremulousness and increased right upper extremity muscle twitching. He denied dysarthria, diplopia, dysphagia, dyspnea, myalgias, or hyperhidrosis, and had no new neck pain. He denied any substantial, known exposure to toxins, infectious agents, or burn pits. He denied family history of neuromuscular disease or motor delay.

Motor examination revealed flaccid tone in the right hand with substantial atrophy affecting the right thenar and hypothenar muscles, as well as the interossei, forearm flexors and extensors, triceps, and pectoralis. The right upper extremity demonstrated grade $4 / 5$ strength in elbow extension, pronation, supination, wrist flexion, and extension, weaker $3 / 5$ digit extension, $2 / 5$ strength in the extensor indicis proprius (EIP), and $3 / 5$ strength in both abductor pollicis brevis, abductor digiti minimi, and first dorsal interosseous. Reflexes were $1+$ in bilateral biceps, brachioradialis, and left triceps; the right triceps was scored 3+. Wartenburg and Hoffman signs were absent. Jaw jerk was normal. Subtle pain and temperature deficits throughout the right fingers, palm, and lateral forearm lacked a clear dermatomal distribution. Tinel sign was absent at the wrists and elbows.

\section{Questions for consideration:}

1. What localizations are possible based on the examination?

2. What other localizations might be considered given the history?

3. What is the significance of the muscle cramping described by the patient?

GO TO SECTION 2 


\section{Section 2}

Motor features predominate, with weakness in multiple territories, including the median, ulnar, and radial distributions, some showing atrophy; at least 1 weak muscle group is hyperreflexic. Although lower trunk weakness predominates, it would be difficult to implicate a single brachial plexus lesion. A patchy plexus injury or multilevel radicular process remains possible, although more sensory features or pain might be expected. Multifocal neuropathy would be considered less likely given the hyperreflexia. Hyperreflexia is suggestive of upper motor neuron involvement, forcing consideration of motor neuron disorders and cervical myelopathy.

Most of these motor-predominant disorders would not produce significant sensory deficits. Given their subtlety and late appearance, the sensory deficits may suggest a secondary process such as superimposed radiculopathy or neuropathy.

Cramping is a nonspecific symptom: while electrical cramp potentials seen during EMG usually suggest motor neuron excitability, patients may use the term to describe difficulty relaxing muscles. This may be present in a variety of motor neuron, nerve, and muscle disorders, and might represent myotonia, paramyotonia, tetany, or neuromyotonia. Myotonia and paramyotonia manifest as impaired muscle relaxation after voluntary contraction: myotonia improves with further exercise while paramyotonia worsens. ${ }^{1}$ Both may be seen in muscle diseases or channelopathies. ${ }^{1}$ Tetany results from repetitive motor unit discharges at high rates, usually due to metabolic disturbance (e.g., hypocalcemia, low vitamin D). Neuromyotonia results from peripheral nerve hyperexcitability leading to muscle contractions, pseudomyotonia, or myokymia. ${ }^{1}$ On later questioning, our patient's impaired relaxation tended to improve with exercise, and he had no known no metabolic derangements: myotonia was suspected.

\section{Questions for consideration:}

1. What is the differential for asymmetric arm weakness?

2. What additional testing should be considered? 


\section{Section 3}

The patient has weakness in multiple nerve distributions with atrophy, subtle sensory deficits, and hyperreflexia. An attempt to consolidate all of the patient's symptoms and signs points most strongly to a slowly progressive cervical myelopathy or multilevel radiculopathy, while downweighting the lateappearing sensory symptoms elevates motor neuron disorders. Other considerations include a multifocal neuropathic process (e.g., multifocal motor neuropathy, multifocal acquired demyelinating sensory and motor neuropathy, vasculitis) or a plexopathy (table). Although most of the above differential can be associated with myotonia on EMG, clinical myotonia, as suggested by the history, is atypical in neurogenic processes. This finding raised concern for underlying condition, such as dystrophic or nondystrophic myotonia, likely unrelated to his isolated weakness and atrophy, as the monomelic presentation would be unusual for these disorders.

Reasonable next steps include cervical spine MRI and electrodiagnostic studies. An extensive battery of tests for plausible metabolic derangements, infections, inflammatory states, and autoimmune conditions may be indicated based on specific features of the time course, examination, health, and exposure history. CSF analysis should be strongly considered to evaluate for infectious, inflammatory, or demyelinating disorders. MRI of the brain or thoracic spine should be considered if there is suspicion of demyelinating disease. MRI of the brachial plexus could be considered.

In our case, an initial neurosurgical evaluation ( 2 years after onset) for suspected acute myelopathy given progressive motor and novel sensory deficits led to a cervical spine MRI showing slight cord atrophy around $\mathrm{C} 5-\mathrm{C} 7$ with mild degenerative disc disease at C5-C6 (figure 1A). Brain MRI was normal. Nerve conduction studies were normal, but highamplitude, long-duration, polyphasic motor units with reduced recruitment were noted in the first dorsal interossei, abductor digit minimi (ADM), flexor carpi radialis, and triceps, with no voluntary units in the EIP. No insertional or spontaneous activity was seen. Repeat testing 2 weeks later largely confirmed these results, while demonstrating fibrillations and positive sharp waves in the EIP, flexor pollicis longus, and triceps. Left medial antebrachial cutaneous sensory, left ulnar motor, and EMG of the left ADM were normal. These findings are consistent with an asymmetric, chronic neurogenic process.

\section{Question for consideration:}

1. What is the most likely diagnosis?

Table Clinical reasoning approach to localization of asymmetric arm weakness

\begin{tabular}{ll}
\hline Localization & Clinical clues \\
\hline Myelopathy & Neck pain, bowel or bladder dysfunction by history; examination with sensory level, long tract signs \\
\hline Radiculopathy & $\begin{array}{l}\text { Neck pain, with radiation into limb in radicular pattern by history; examination with sensory or motor deficits in specific root } \\
\text { territory, decreased reflex in specific root territory }\end{array}$ \\
\hline Brachial plexopathy & $\begin{array}{l}\text { Traumatic or radiation injury to upper extremity in past, axillary pain followed by weakness, sensory deficits by history } \\
\text { (brachial plexitis), examination with sensory or motor deficits in multiple nerve territories }\end{array}$ \\
\hline Motor neuron disease & $\begin{array}{l}\text { Absence of sensory complaints, report of fasciculations by history, examination with upper (long tract signs) and lower } \\
\text { (atrophy, fasciculation) motor findings }\end{array}$ \\
\hline $\begin{array}{l}\text { Multifocal peripheral } \\
\text { neuropathy }\end{array}$ & Stepwise loss of function in multiple nerve distributions by history, examination with deficits in multiple territories \\
\hline
\end{tabular}


Figure MRI of cervical spine

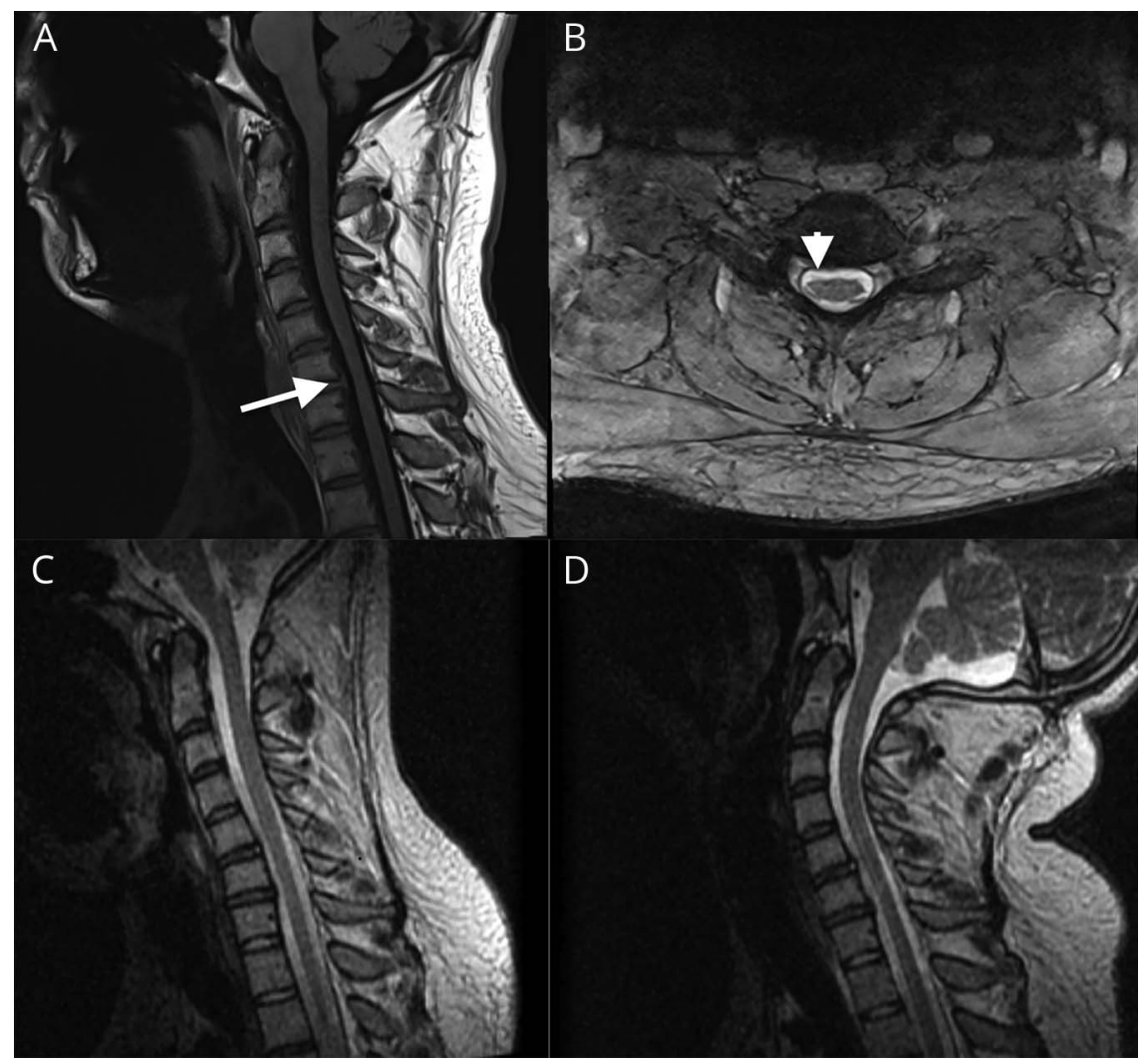

(A) T1-weighted fluid-attenuated inversion recovery sagittal image demonstrates flattening of posterior cervical spinal cord at C5-C7 (arrow). (B) T2-weighted axial image demonstrates right greater than left flattening of posterior cervical spinal cord (arrowhead). T2-weighted sagittal flexion (C) and extension (D) images fail to demonstrate compression of the cord against the vertebral bodies; however, neck may not be maximally flexed. 


\section{Section 4}

Given the clinical history, examination findings, and diagnostic studies, the patient was diagnosed with juvenile monomelic amyotrophy (JMA, also known as juvenile muscular atrophy of distal upper extremity, focal amyotrophy, or Hirayama disease). No systemic symptoms suggested an ongoing infectious or autoimmune process and motor symptoms were largely stable; lumbar puncture was deferred, but in most cases, should be strongly considered along with additional laboratory workup. MRI of the cervical spine with flexion and extension should be considered given the flexion myelopathy to which JMA is sometimes ascribed. CT venogram could be considered if there is concern for venous congestion causing anterior displacement. ${ }^{3}$

\section{Questions for consideration:}

1. What is the expected disease progression in JMA?

2. Is the clinical symptom of possible myotonia related to the JMA diagnosis? 


\section{Section 5}

The expected pattern of disease in JMA is of slowly progressive unilateral (and occasionally bilateral) weakness in an upper extremity. Patients typically develop atrophy, polyminimyoclonus in the outstretch fingers, and transient worsening on cold exposure without clear involvement of sensory or pyramidal tracts. The disease usually arrests spontaneously with minimal recovery.

Re-examination 3 years after symptom onset showed no evidence of progression. Five years after onset, repeat evaluation was prompted by worsening episodes of forearm spasms and hand cramping, worse on the right, worse in cold, and improved with exercise. The patient denied progression of weakness. Examination disclosed a fine, high-frequency, lowamplitude, semi-rhythmic postural and kinetic tremor. Tone was normal. There was no eyelid, tongue, grip, or percussion myotonia. Strength was unchanged (section 1). Reflexes were $2+$ in the left upper extremity and $3+$ on the right. Sensory examination revealed subtle decreases in pinprick throughout the right palm, fingers, and lateral forearm without clear dermatomal distribution.

The tremulousness was believed to represent polyminimyoclonus, reported in JMA and other motor neuron diseases. ${ }^{4}$ Flexion and extension cervical spine MRI (figure 1, $\mathrm{C}$ and $\mathrm{D}$ ) re-demonstrated flattening of the right cervical cord with no more than mild disc protrusions or nerve root compression. MRI of the brain and brachial plexus were normal. Electrodiagnostic studies were largely unchanged, save for the finding of fibrillations, positive waves, and myotonic discharges in the right flexor digitorum profundus.

Electrical myotonia is commonly reported in myotonic dystrophies and channelopathies but may be encountered in chronic processes involving damaged motor axons. Given the neurogenic muscle atrophy of JMA, the occurrence of electrical myotonia may not be surprising. However, clinical myotonia is not well-reported in the neurogenic disorders where its electrical presence is noted. Coupled with exacerbation by cold weather, its presence here might raise concern for an underlying muscle disorder. However, exacerbation by cold is reported in both JMA and the dystrophic and nondystrophic myotonias, perhaps due to underlying muscle fiber hyperexcitability secondary to ion channel dysfunction. ${ }^{2}$ Upon further questioning, the patient reported a maternal family history of diabetes and early cataracts, prompting genetic testing for myotonic muscular dystrophy types 1 and 2, which was negative, as well as a more extensive EMG, which failed to reveal additional muscles with myotonic discharges.

\section{Discussion}

This case emphasizes the broad differential for unilateral distal upper extremity weakness, atrophy, and upper motor neuron signs. Localization and clinical reasoning were complicated by both sensory symptoms and the presence of clinical and electrical myotonia, necessitating evaluation for other central and peripheral disorders. Despite this, the stability of motor symptoms over time helped clarify the diagnosis.

Clinical criteria for JMA include gradual onset of predominantly asymmetric, distal weakness and atrophy of forearm and hand muscles, particular hand intrinsics and ulnar forearm muscles (C7-T1 innervated muscles), onset in the first to third decade of life, and gradual progression over years (usually less than 5) before stabilization. ${ }^{2}$ History and examination should reveal normal lower extremities, sensation, normal to hypoactive reflexes, and can classically spare brachioradialis. In about $30 \%$ of patients, bilateral involvement may occur. ${ }^{2}$ Associated features include exacerbation with cold temperatures, polyminimyoclonus, and fasciculations in both atrophic and normal-appearing muscles. ${ }^{2,4}$ Electrodiagnostic testing may reveal low-amplitude median or ulnar compound motor action potentials with preserved sensory potentials. EMG will show chronic denervation and reinnervation during progression; reinnervation predominates late. Dynamic flexion MRI can demonstrate forward displacement of the cervical dural sac with compressive flattening of the lower cervical cord. ${ }^{2}$ The mechanism is unknown: hypotheses include flexion myelopathy caused by flattening of the lower cervical cord against the posterior surface of the vertebra, venous congestion, or chronic ischemic myelopathy with involvement of the anterior horns. Autopsies have shown atrophied anterior horn cells, reduced number of both large and small motor neurons, and spinal cord flattening. ${ }^{2}$

Literature searches for clinical or electrodiagnostic myotonia with JMA did not reveal any results. Araki $^{5}$ reported myotonia-like symptoms in a patient with spinal and bulbar muscular atrophy, but without electrodiagnostic evidence of myotonia. The appearance of this striking electrodiagnostic finding does not appear to exclude JMA.

\section{Author contributions}

E.J. Elliot: drafting, revision of manuscript. J.K. Smith: revision of manuscript for content.

\section{Study funding}

No targeted funding reported.

\section{Disclosure}

The authors report no disclosures relevant to the manuscript. Go to Neurology.org/N for full disclosures.

\section{References}

1. Fearon C, Murray B, Mitsumoto H. Bradley's Neurology in Clinical Practice, 7th ed. Philadelphia: Elsevier; 2016.

2. Darras BT, Markowitz JA, Monani UR, De Vivo DC. Neuromuscular Disorders of Infancy, Childhood, and Adolesence, 2nd ed. Philadelphia: Elsevier; 2015: $117-145$.

3. Wuang MW, Grossman AW, Barmada S, Josephson SA, Dillow W, Ralph JW. Pearls \& Oy-sters: the use of CT venography in Hirayama disease. Neurology 2012;79: e38-e40.

4. Ong J, Wang F, Chan Y. Teaching NeuroImages: a case of Hirayama disease presenting with polymyoclonus. Neurology 2015;85:e156-e157. 
5. Araki K, Nakanishi H, Nakamura T, et al. Myotonia-like symptoms in a patient with spinal and bulbar muscular atrophy. Neuromuscul Disord 2015;25:913-915.

6. Wingerchuck DM. Infectious and inflammatory myelopathies. Continuum: Lifelong Learn Neurol 2008; 14:36-57.

7. Overview to approach to the patient with noncompressive myelopathy. Continuum: Lifelong Learn Neurol 2005;11:13-24.
8. Schwendimann RN. Metabolic and toxic myelopathies. Continuum: Lifelong Learn Neurol 2018;24:427-440.

9. Goutman SA. Diagnosis and clinical management of amyotrophic lateral sclerosis and other motor neuron disorders. Continuum: Lifelong Learn Neurol 2017;23:1332-1359.

10. Grill MF. Infectious myelopathies. Continuum: Lifelong Learn Neurol 2018;24: $441-473$. 


\section{Neurology}

Clinical Reasoning: A 26-year-old man with right hand and arm weakness

Emily J. Elliott and Jonathan K. Smith

Neurology 2019;93;e927-e933

DOI 10.1212/WNL.0000000000008006

This information is current as of August 26, 2019

\section{Updated Information \&} Services

\section{References}

Subspecialty Collections

\section{Permissions \& Licensing}

\section{Reprints}

including high resolution figures, can be found at: http://n.neurology.org/content/93/9/e927.full

This article cites 8 articles, 2 of which you can access for free at: http://n.neurology.org/content/93/9/e927.full\#ref-list-1

This article, along with others on similar topics, appears in the following collection(s):

\section{All Spinal Cord}

http://n.neurology.org/cgi/collection/all_spinal_cord

Anterior nerve cell disease

http://n.neurology.org/cgi/collection/anterior_nerve_cell_disease Clinical neurology examination

http://n.neurology.org/cgi/collection/clinical_neurology_examination

Clinical neurology history

http://n.neurology.org/cgi/collection/clinical_neurology_history

Muscle disease

http://n.neurology.org/cgi/collection/muscle_disease

Information about reproducing this article in parts (figures,tables) or in its entirety can be found online at:

http://www.neurology.org/about/about_the_journal\#permissions

Information about ordering reprints can be found online:

http://n.neurology.org/subscribers/advertise

Neurology ${ }^{\circledR}$ is the official journal of the American Academy of Neurology. Published continuously since 1951, it is now a weekly with 48 issues per year. Copyright @ 2019 American Academy of Neurology. All rights reserved. Print ISSN: 0028-3878. Online ISSN: 1526-632X.

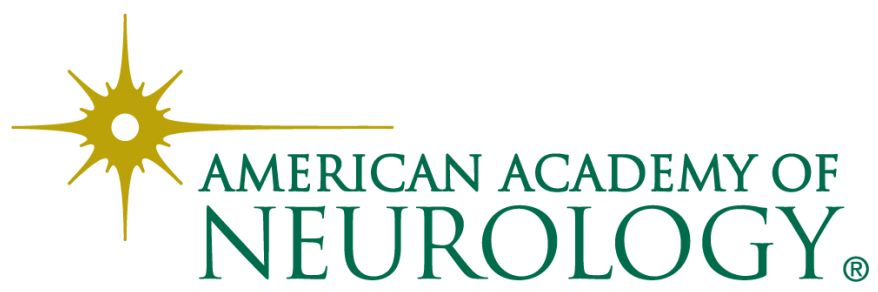

